Niebuhr, E. (1972a). A 45,XX,5-,13-,dic+ karyotype in a case of cri-du-chat syndrome. Cytogenetics, 11, 165-177.

Niebuhr. E. (1972b). Dicentric and monocentric Robertsonian translocations in man. Humangenetik, 16, 217-226.

Pallister. P. D., Patau, K., Inhorn. S. L., and Opitz, J. M. (1974). A woman with multiple congenital anomalies, mental retardation and mosaicism for an unusual translocation chromosome $t$ (6:19). Clinical Genetics, 5, 188-195.

Seabright. M. (1971). A rapid banding technique for human chromosomes. Lancet, 2, 971-972.

Sears. E. R., and Câmara. A. (1952). A transmissible dicentric chromosome. Genetics, 37, 125-135.

Sumner. A. T. (1972). A simple technique for demonstrating centromeric heterochromatin. Experimental Cell Research, 75, 304306.

Walker. N. F. (1957). The use of dermal configurations in the diagnosis of mongolism. Journal of Pediatrics, 50, 19-26.

Requests for reprints to $\operatorname{Dr}$ Angela M. ViannaMorgante, Laboratório de Genética Humana, Departamento de Biologia, Instituto de Biociências, Universidade de São Paulo, Brazil.

\section{Translocation of chromosome 4 and 9 with ring formation of chromosome 4 short arm}

SUMMARY Cytogenetic investigation of a 3year-old mentally retarded boy revealed a translocation of the long arm of chromosome 4 onto the short arm of chromosome 9, with ring formation of the remaining short arm of chromosome 4 . The clinical features are described and correlated with the cytogenetic findings. The behaviour of the ring derived from a deleted chromosome 4 is discussed.

Structural abnormalities of chromosome 4 have been reported on many previous occasions. Borgaonkar and Dolling (1977) list over 40 translocations involving this chromosome, and the recipient has been found to include all chromosome groups except group F. In the C-group chromosomes, there is no report of chromosome 9 being involved in a translocation with chromosome 4. Deletion of the short arm of chromosome 4 has been sufficiently well documented to present a clinically identifiable syndrome, Wolf's syndrome (Guthrie et al., 1971), but no distinct phenotype has yet been delineated for long arm deletions of this chromosome (Van Kempen, 1975). Ring formation of chromosome 4, however, has been reported very rarely, only 8 cases being quoted by McDermott et al. (1977), one of these showing a complex rearrangement of chromosome 4 with ring formation (Bobrow et al., 1971). We wish to report a complex abnormality, involving a translocation of chromo-: somes 4 and 9 , with ring formation of the remaining portion of chromosome 4 .

\section{Case report}

A 3-year-old boy was referred for investigation of mental retardation of unknown aetiology. He wass born 3 weeks prematurely, after an uneventfu 5 pregnancy and a prolonged labour, to young unrelatedparents of normal intelligence. The father was $25 \overrightarrow{\mathrm{s}}$ years old and the mother 27 years old. There was no history of miscarriages or stillbirths. His birthweigh was $2200 \mathrm{~g}$ and he was placed in an incubator for $\dot{\varepsilon}$ weeks postnatally because of respiratory problems (hyaline membrane disease?). At 2 months he had $\dot{\alpha}$ severe attack of gastroenteritis necessitating intra 0 venous fluid replacement, and he developed an eas infection at 6 months. He has had no serious infectionssince then. At 9 months of age his parents became concerned about his slow development. He sae

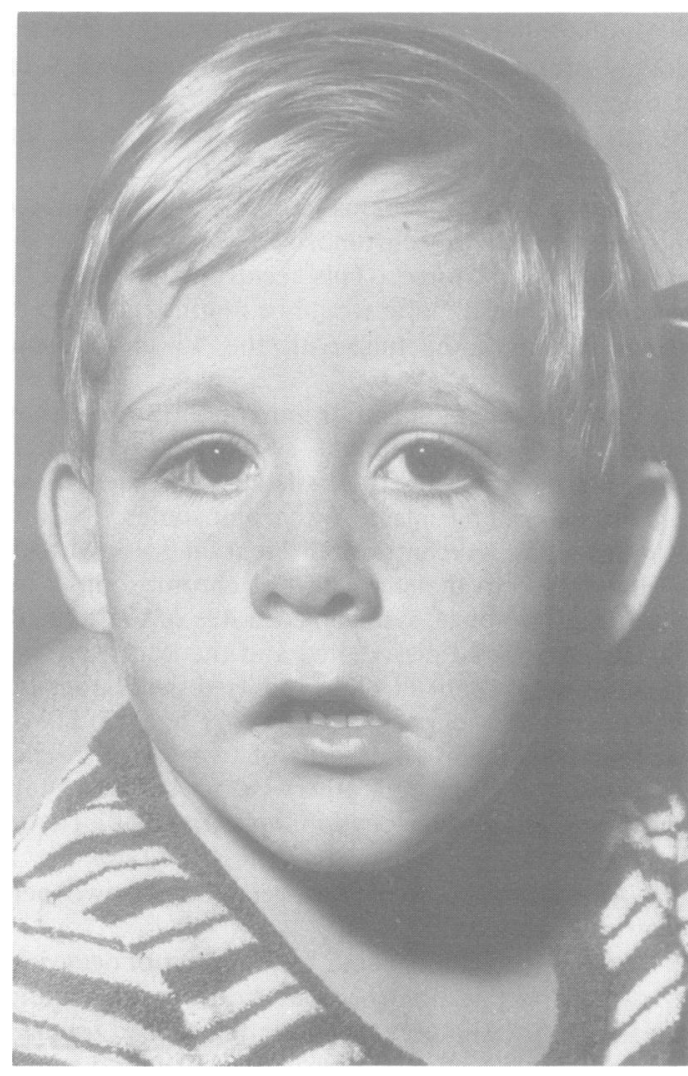

Fig. 1 Facial appearance of proband at 3 years of age. 
unassisted at 13 months and first walked on his own when nearly 2 years old. He spoke a few words at 2 years; at 3 years his vocabulary was still very limited and his comprehension was poor. He has always been an irritable, restless, hyperactive child. He was found to have a small head at 16 months. There was no relevant family history, apart from a maternal cousin who had a spastic retarded female child with cataracts who died at 4 years of age, without a specific diagnosis having been made.

Examination at 3 years revealed an obviously mentally retarded, irritable child. His height was 84 $\mathrm{cm}$, weight $10 \mathrm{~kg}$, and head circumference $46 \mathrm{~cm}$ (all below the 3 rd centile). His physical appearance was not grossly abnormal apart from a slight asymmetry of the face, the right side being smaller than the left. There was mild bilateral ptosis and a mild convergent squint of the right eye. The ears were large, simple, and slightly low set. The upper lips were thin, downcurved, and 'carp-like' (Fig. 1). The penis was of normal size with a terminal urethral meatus. Both testes were undescended, the right testis being palpable in the inguinal canal. There was slight clinodactyly of the 5th fingers and an incomplete single palmar crease on the left hand, but the right palmar creases were normal. The child was hypotonic, but all reflexes were normal. No other internal or external abnormalities were noted.

Dermatoglyphic patterns were unremarkable. Ulnar loops were present on 9 of 10 fingers with a radial loop on the 2nd finger of the right hand. The total finger ridge count was 108 . The palmar axial triradii were proximally placed, and the atd angles of the right and left palms were $43^{\circ}$ and $48^{\circ}$, respectively. The thenar and hypothenar spaces of both hands showed an open pattern. The total $a-b$ ridge count was 80 . A distal loop was present in the 4th interdigital areas of both hands.

Special investigations included studies for the detection of toxoplasmosis, rubella, and cytomegalovirus antibodies; these were all negative. There was no aminoaciduria. A lumbar puncture at 16 months showed no abnormality, but an air-encephalogram showed a minimal amount of free air over the surfaces of the cortex, consistent with mild generalised cortical atrophy. An electroencephalogram at 2 years of age showed bilateral dysfunction compatible with an epileptiform pattern. He was therefore given phenobarbitone though there was no history of fits.

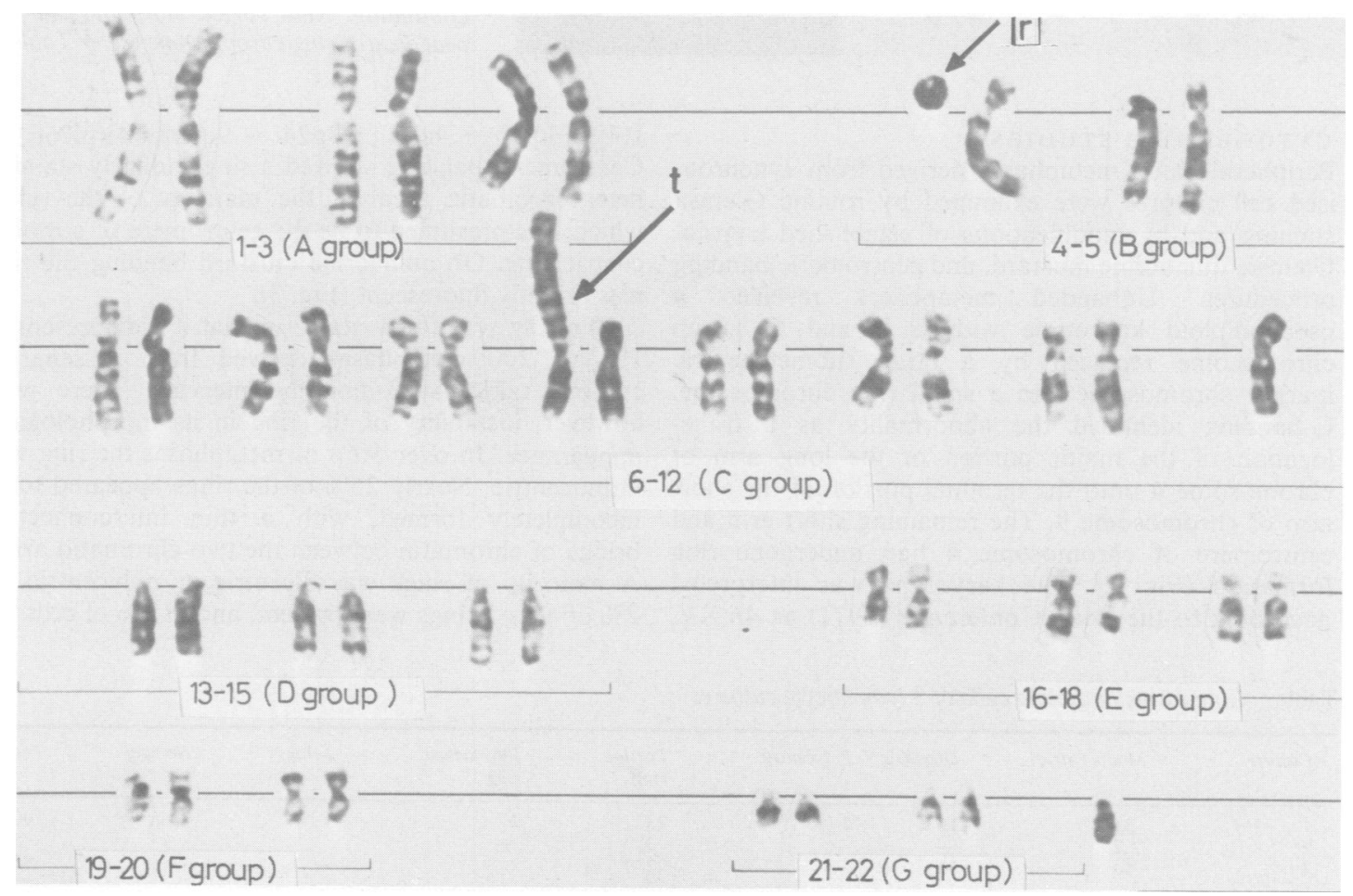

Fig. 2 A Giemsa-banded karyotype showing ring $4 p(r)$ and long arm of chromosome 4 translocated onto short arm of chromosome $9(t)$. 


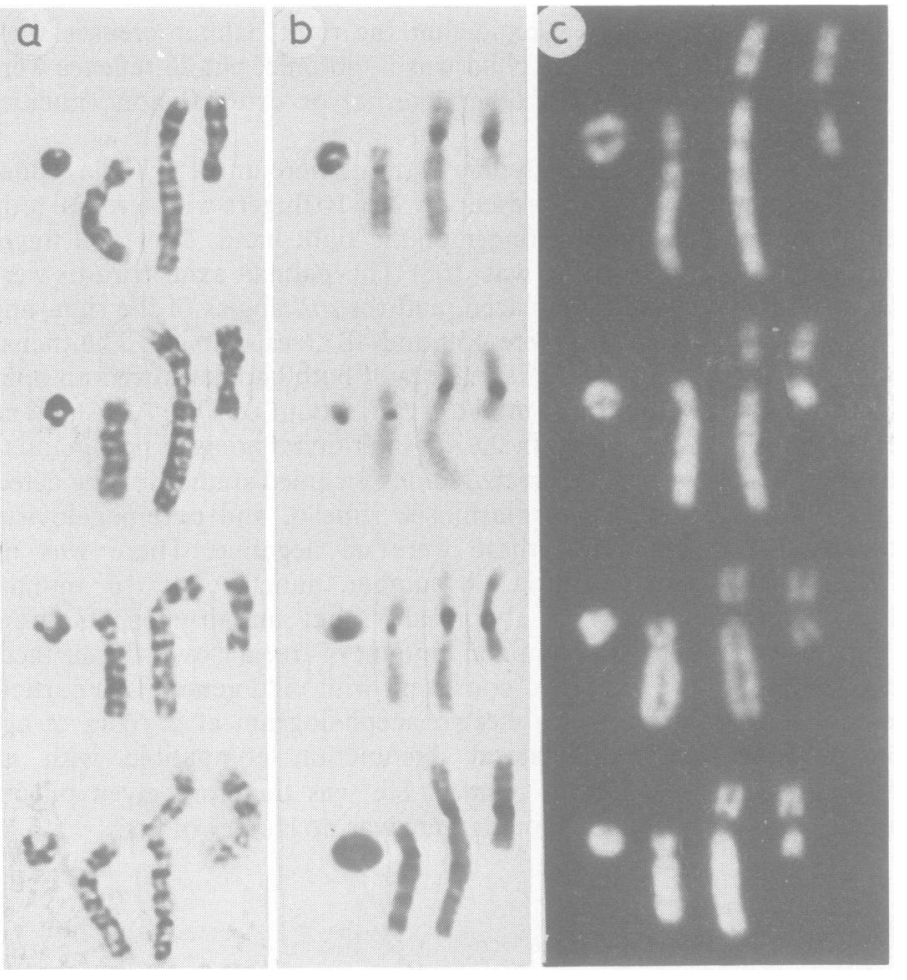

Fig. 3 Twelve partial karyotypes of chromosomes 4 and 9 , showing from left te right, ring $4 p$, normal 4 homologue, $t(4 ; 9) \frac{1}{4}$ chromosome, and normal 9 homologue (inverted). (a) G-banding; (b) C-banding; (c) $Q$-banding. Note varied morphological ap $\infty$ pearance of ring chromosome (refer Table).

\section{CYTOGENETIC STUDIES}

Peripheral blood metaphases derived from synchronised cell cultures were examined by routine Giemsa staining and by modifications of established trypsinGiemsa, quinacrine mustard, and centromeric banding procedures. Unbanded metaphases revealed a pseudodiploid karyotype with a B and C group chromosome replaced by a large submetacentric marker chromosome and a small ring chromosome. G-banding identified the abnormality as a translocation of the major portion of the long arm of chromosome 4 onto the terminal portion of the short arm of chromosome 9. The remaining short arm and centromere of chromosome 4 had undergone ring formation (Fig. 2). The karyotype was interpreted according to the Paris Conference (1971) as 46,XY, $\mathrm{t}(4 ; 9)(4 \mathrm{qter} \rightarrow$ 4q12 :: 9p24 $\rightarrow$ 9qter),r(4)(pl?6q12)@ Centromeric banding showed a single, darkly staining heterochromatic area on the majority of the rings which was presumed to be the centromere of a mono윽 centric ring. On quinacrine mustard banding the ring was brightly fluorescent (Fig. 3).

The ring was fairly stable in that it was present in 193 of 200 metaphases derived from 3 separate्ठ cultures taken at 3-monthly intervals. There was:however, instability of the ring in its morphologica $\mathrm{B}$. appearance. In over $50 \%$ of metaphases the ring was monocentric. Nearly $25 \%$ of the rings appeared to be incompletely formed, with a thin interconnecting bridge of chromatin between the two chromatid arms A minority of rings was dicentric or polycentric. In $2 \%$ of cells 2 rings were present, and in $2 \%$ of cells the

Table Ring forms in diploid cells of 3 lymphocyte cultures

\begin{tabular}{|c|c|c|c|c|c|c|c|c|}
\hline Culture & Monocentric & Dicentric & Polycentric & $\begin{array}{l}\text { Partial } \\
\text { ring }\end{array}$ & $\begin{array}{l}\text { Interlocked } \\
\text { ring }\end{array}$ & 2 rings & No ring & Total \\
\hline $\begin{array}{l}1 \\
2 \\
3\end{array}$ & $\begin{array}{r}55 \\
2 \\
46\end{array}$ & $\frac{11}{16}$ & $\frac{2}{5}$ & $\begin{array}{r}23 \\
3 \\
22\end{array}$ & $\frac{2}{2}$ & $\frac{4}{-}$ & $\frac{3}{4}$ & $\begin{array}{r}100 \\
5 \\
95\end{array}$ \\
\hline Total & 103 & 27 & 7 & 48 & 4 & 4 & 7 & 200 \\
\hline
\end{tabular}


ring had a 'figure-of-eight' interlocked appearance (Table, Fig. 3). The exact area of breakage on the distal portion of $4 p$ could not be precisely defined because of the 'fuzzy' nature and lack of identifiable banding patterns on the ring, but judging from the size of the ring, it appeared to be near the terminal area. Both parents had normal karyotypes.

\section{GENE MARKER STUDIES}

Attempts to exploit this family for establishing or confirming assignment of gene loci have been unsuccessful. There was no variation at the $\mathbf{P G M}_{2}$ locus (previously assigned to chromosome 4), or at the $\mathrm{ABO}$ and $\mathrm{AK}$ loci (assigned to chromosome 9) (McKusick and Ruddle, 1977). No anomalous segregation was evident for genes at the Rhesus, blood group $\mathrm{P}$, red cell acid phosphatase, or haptoglobin loci. There was no informative variation at the following loci: MNSs, Kell, Duffy, G6PD, 6PGD, ADA, $\mathrm{PGM}_{1}$, peptidases $\mathrm{A}$ and $\mathrm{D}$, est $\mathrm{D}, \mathrm{CA}_{\mathrm{I}}, \mathrm{CA}_{\mathrm{II}}$, GPT, ICD, glutathione peroxidase, glyoxylase I, Hb $\alpha, \beta$, and $\delta$ chains, and transferrin.

\section{Discussion}

The proband presented with mental retardation associated with minimal physical stigmata; there was no phenotypic resemblance to any known specific syndrome. The translocation of the long arm of chromosome 4 onto chromosome 9 appears to be morphologically balanced. There was no identifiable loss of bands at break points $4 \mathrm{q} 12$ or $9 \mathrm{p} 24$, but one must assume that submicroscopic loss of genetic material could have occurred. The unusual feature of this case is the ring formation in the remaining portion of chromosome 4 . Ring formation following a translocation implies the occurrence of a third break after the translocation, in this case at the distal portion of the short arm of 4, with subsequent fusion of the broken ends at $\mathrm{q} 12$ and $\mathrm{pl}$ ?6. The exact distal break point could not be accurately identified, but is presumed to be terminal because of the size of the ring and the minimal physical abnormalities in comparison with the gross phenotypic abnormality described in Wolfs $4 \mathrm{p}^{-}$syndrome (Guthrie et al., 1971). The typical clinical features of this syndrome are thought to be associated with loss of the $4 \mathrm{p} 16$ band (Rethore, 1977). Some of the features of the $4 p^{-}$syndrome were present in the child reported here. They were mental deficiency, growth retardation, microcephaly, low set, simple ears, strabismus, downturned mouth, facial asymmetry, and epileptiform electroencephalographic waves (though no seizures have occurred to date). The dermatoglyphic patterns were similar to those described by Bobrow et al. (1971) and Parker et al. (1974) in that their patients also showed 9 ulnar loops, but were otherwise unremarkable.
The spectrum of abnormality described in ring 4 chromosomes has ranged from those patients who have shared some of the features of Wolf's syndrome (Carter et al., 1969; Hecht, 1969; Bobrow et al., 1971; Parker et al., 1974) to those with minimal physical features, but with mental retardation, such as our patient and the patient described by McDermott et al. (1977). Two patients have been described who were of normal intelligence (Dallaire, 1969; Surana et al., 1971). Dallaire's patient and a patient described by Faed et al. (1969) had multiple skeletal abnormalities.

The degree of phenotypic abnormality associated with ring formation will obviously depend on the amount of genetic material deleted, the stability of the ring, and the variability of the ring's genetic content due to the production of variant daughter rings. Kistenmacher and Punnett (1970) postulate that the genetic content of a ring may in turn determine its stability. The ring 4 chromosomes described by Hecht (1969), Carter et al. (1969), Faed et al. (1969), and Parker et al. (1974) have all shown evidence of instability leading to missegregation with resultant mosaicism, breakage, and polycentric ring formation by sister chromatid exchange (Hecht, 1969). However, Bartram (1977) did not observe any increase in sister chromatid exchanges in a ring 4 chromosome investigated after 2 replication cycles in the presence of BrdU. These dicentric and tetracentric rings may undergo breakage and reunion at anaphase leading to rings of unequal size. The ring 4 described by Bobrow et al. (1971) was characterised by anaphase bridges, yet showed stability at metaphase. In the present instance, the formation of the ring was complicated by the fact that the ring was formed from only part of chromosome 4, after translocation of the major portion of the chromosome onto another chromosome. In the case of Bobrow et al. (1971), the major portion of the long arm of chromosome 4 formed a ring, whereas in our patient the ring formation involved the short arm of chromosome 4. Mosaicism of the ring was not a prominent feature in the present case; $3.5 \%$ of cells were monosomic, and $2 \%$ of cells were disomic for the ring in peripheral blood lymphocytes. There was, however, a definite instability of the ring as evidenced by the number of incomplete rings, dicentric, polycentric, and interlocking rings. One must, therefore, presume that there is great variability in the genetic content of the ring from cell to cell.

Correlation of the abnormal phenotype with the karyotypic findings is therefore modified in this case by at least 2 operative factors: the effects of the translocation, and the varied genetic content duc to instability of a ring formed from a partial chromosome segment. 
We thank Mrs. P. Craig for technical assistance; and Mrs. Y. Desy and Mr. M. Ulrich for photographic assistance.

Renée Bernstein, Anthony T. Milne, AND TREFOR JENKINS

Department of Human Genetics, School of Pathology, The South African Institute for Medical Research and University of the Witwatersrand, Johannesburg

References

Bartram, C. R. (1977). Sister chromatid exchanges in a ring chromosome 4. Cytogenetics and Cell Genetics, 18, 238-241.

Bobrow, M., Jones, L. F., and Clarke, G. (1971). A complex chromosomal rearrangement with formation of a ring 4. Journal of Medical Genetics, 8, 235-239.

Borgaonkar, D. S., and Dolling, D. R. (1977). Repository of Chromosomal Variants and Anomalies in Man. Fourth Listing, April 1977. The Johns Hopkins University, Baltimore.

Carter, R., Baker, E., and Hayman, D. (1969). Congenital malformations associated with a ring 4 chromosome. Journal of Medical Genetics, 6, 224-227.

Dallaire, L. C. (1969). A ring B chromosome in a female with multiple skeletal abnormalities. Birth Defects: Original Article Series, 5, 114-116. The National Foundation-March of Dimes, New York.

Faed, M., Stewart, A., and Keay, A. J. (1969). Chromosome abnormalities in two cases with bilateral radial element defects. Journal of Medical Genetics, 6, 342-346.

Guthrie, R. D., Aase, J. M., Asper, A. C., and Smith, D. W. (1971). The $4 \mathrm{p}^{-}$syndrome. American Journal of Diseases of Children, 122, 421-425.

Hecht, F. (1969). Ring-4 chromosome : ring autosomes, Lorelei of clinical-karyotype correlation and deletion mapping. Birth Defects: Original Article Series, 5, part 5, 106-113. National Foundation-March of Dimes, New York.

Kistenmacher, M. L., and Punnett, H. H. (1970). Comparative behaviour of ring chromosomes. American Journal of Human Genetics, 22, 304-318.

McDermott, A., Voyce, M. A., and Romain, D. (1977). Ring chromosome 4. Journal of Medical Genetics, 14, 228-232.

McKusick, V. A., and Ruddle, F. H. (1977). The status of the gene map of the human chromosomes. Science, 196, 390-405.

Paris Conference (1971). Standardization in human cytogenetics. Birth Defects: Original Article Series, 8, No. 7, 1972. The National Foundation-March of Dimes, New York.

Parker, C. E., Alfi, O. S., Derenesenyi, A., Mavalwala, J., and Donnell, G. (1974). A child with a ring-4 chromosome (46,XX/46,XX,+4). American Journal of Diseases of Children 128, 371-374.

Rethoré, M. O. (1977). Relations between aneuploidy and development. Plenary Address. Fifth International Conference on Birth Defects, Montreal, Canada, 21-27 August, 1977.

Surana, R. B., Bailey, J. D., and Conen, P. E. (1971). A ring-4 chromosome in a patient with normal intelligence and short stature. Journal of Medical Genetics, 8, 517-521.

Van Kempen, C. (1975). A patient with congenital anomalies and a deletion of the long arm of chromosome 4(46,XY,del(4)(q31). Journal of Medical Genetics, 12, 204-207.

Requests for reprints to Dr R. Bernstein, Cytogenetic Unit, Department of Human Genetics, South African Institute for Medical Research, P.O. Box 1038, Johannesburg 2000, South Africa.
Bilateral renal agenesis in 2 male sibs born to consanguineous

\section{parents}

SUMMARY Two boys with bilateral agenesis of kidneys and ureters were the product of aw consanguineous marriage. This family and pre- $\overrightarrow{0}$ vious reports of familial bilateral renal agenesissupport the supposition that a minor proportion $\vec{\omega}$ of cases of BRA is caused by the homozygousstate of an autosomal recessive gene.

\section{Case reports}

The pedigree of the family is shown in the Fig. Both parents (IV.7 and IV.8) were healthy and came from a village near Naples, Southern Italy. The father's mother and the mother's maternal grandfather were sibs. The family history was otherwise unremarkable ${ }^{\infty}$ except for one stillbirth for unknown reasons (V.4).

The gestational histories and perinatal courses of both patients were essentially identical and therefore are reported simultaneously, with any variation in the second sib shown in parentheses. There was no history of drug intake. Oligohydramnios was noticed duringo the second trimester, and spontaneous delivery from ao vertex presentation took place in the 35th (36th) week of gestation. The prematurely born male infantso을 suffered from severe neonatal asphyxia which, despite efforts at respiration, led to death 11 (8) hours after birth. The probands were anuric, and no kidneys were. evident either on palpation or on $x$-ray. Birthweights $\overline{3}$ $(2250 \mathrm{~g}$ and $2500 \mathrm{~g}$, respectively) were normal for gestational ages of 35 and 36 weeks. Dysmorphic 3 features in the 2 sibs were similar and typical of the oligohydramnios tetrad. They included a wrinkled? senile-looking face with receding forehead, widely spaced eyes, inner epicanthal folds extending down-5 wards to the middle of the cheeks, a bird-like nose, an $\frac{7}{0}$ underdeveloped chin, low-set, folded, and misshapen ears, narrow chest, scoliosis of the thoracic spine, and $N$ short, broad hands with tapering fingers. The younger sib, in addition, had right cryptorchidism and his placenta contained a single umbilical artery. Neither of $\omega$ them had club feet or other significant limb positioning defects.

Necropsies showed bilateral renal and ureteral agenesis, with hypoplasia of the urinary bladder, pulmonary hypoplasia with hyaline membranes and $\frac{0}{\circ}$

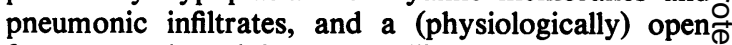
foramen ovale and ductus Botalli. 